\title{
Are we on brink of a second COVID-19 wave in Italy? Let's look at Google Trends
}

\author{
Jacopo Ciaffi ${ }^{1}$ (1) Riccardo Meliconi ${ }^{1,2} \cdot$ Maria Paola Landini ${ }^{3} \cdot$ Francesco Ursini $^{1,2}$
}

Received: 23 August 2020 / Accepted: 5 September 2020 / Published online: 17 September 2020

(c) Società Italiana di Medicina Interna (SIMI) 2020

\section{Dear Editor,}

Last May, we published on your Journal the article "Google Trends and COVID-19 in Italy. Could we brace for impact?" [1]. Using the open-access tool Google Trends ${ }^{\mathrm{TM}}$, we reported the observation of a strong and significant temporal correlation between volumes and patterns of queries for the specific Italian search terms "febbre" and "tosse", respectively, meaning "fever" and "cough" in English translation, and the increase in admissions to intensive care units (ICU) or the number of new deaths from COVID-19 in Italy. Our idea was that the analysis of Google Trends ${ }^{\mathrm{TM}}$ data could have a complementary role to conventional public health surveillance systems in anticipating future outbreaks, with the key purpose of giving the healthcare system enough time to get prepared.

After a transient deflection of the epidemic curve between June and July, we have been witnessing in the last weeks a steady rise of new confirmed cases. In particular, the 947 positive tests recorded on August 21st, represent the highest number since May, when Italy was on the tail end of the first COVID-19 wave and the rigid lockdown measures started to be eased. Official data are accessible on the Italian Government's website https://www.salute.gov.it.

In the light of this evolution, we thought again to Google Trends ${ }^{\mathrm{TM}}$. This time, we couldn't perform a correlation analysis similar to our previous study because, notwithstanding

Jacopo Ciaffi

jacopo.ciaffi91@gmail.com

1 Medicine and Rheumatology Unit, IRCCS Istituto Ortopedico Rizzoli (IOR), via Pupilli 1, 40136 Bologna, Italy

2 Department of Biomedical and Neuromotor Sciences (DIBINEM), Section of Rheumatology, University of Bologna, Bologna, Italy

3 Scientific Direction, IRCCS Istituto Ortopedico Rizzoli (IOR), Bologna, Italy the overt surge in new infections, the number of patients needing ICU, as well as the fatalities per day, is relatively low and almost invariably in single figures, thus precluding any robust statistical approach. Moreover, since a relevant percentage of the infected individuals identified in the last weeks result from contact tracing independently of clinical manifestations, in our opinion, quantifying the correlation between volumes of potential symptoms search and number of new, largely asymptomatic, cases, would not be entirely appropriate.

However, we wondered whether Google Trends ${ }^{\mathrm{TM}}$ data could mirror again the dynamics of virus spread or not. With this in mind, we plotted the daily number of new cases against the synchronous search volumes for "febbre" and "tosse" in the period from May 1st, 2020 to August 21st, 2020. (Fig. 1a, b). With the aid of polynomial smoothed trendlines to facilitate visual appraisal of data, we observed the gentle upward curving of search volumes appearing since the end of June, shortly before the number of new confirmed COVID-19 cases started rising again.

Consistently with the methodology applied to our original study and to corroborate the findings, we also plotted the proportion of interest toward commonly occurring symptoms not directly related to COVID-19 infection [2] and the number of new COVID-19 cases. The same period of time was selected and Google Trends ${ }^{\mathrm{TM}}$ for the Italian words "mal di schiena" and "diarrea", corresponding to "back pain" and "diarrhea" in English translation, were assessed. In this case, no similarities in temporal trends could be identified (Fig. 1c, d), thus supporting the idea that our observations regarding "febbre" and "tosse" were probably not spurious.

We are, therefore, reaffirming the role of infoveillance [3] and we encourage competent health authorities to look seriously at Google Trends ${ }^{\mathrm{TM}}$ to integrate and strengthen traditional surveillance systems aiming at early detection and, potentially, anticipation of future outbreaks, thus allowing stakeholders and healthcare services to take action accordingly. 

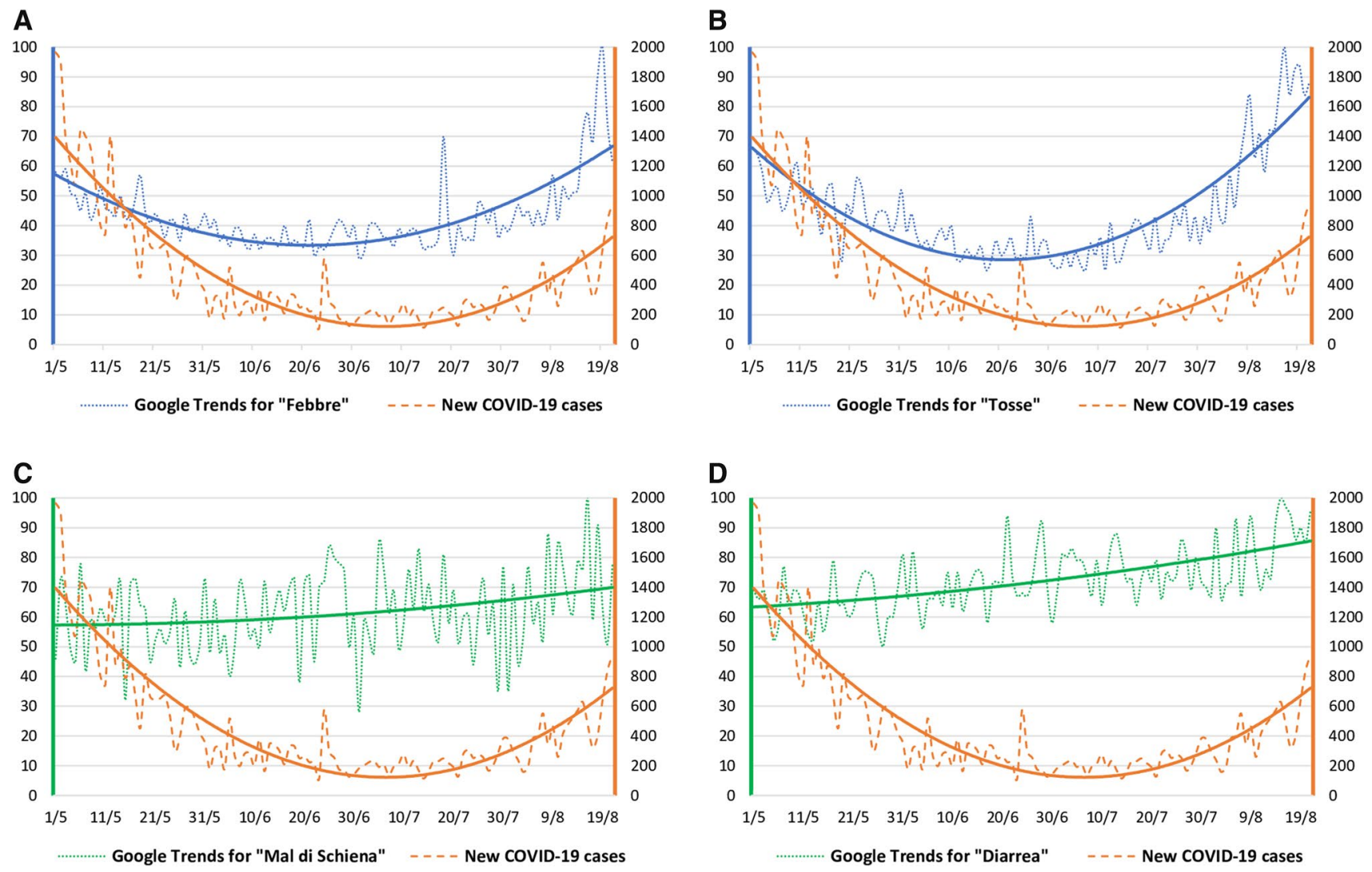

Fig. 1 New confirmed COVID-19 cases between May 1st and August 21st, 2020, plotted against Google Trends' search volumes of the Italian words "febbre" (panel A), "tosse" (panel B), "mal di schiena" (panel C) and "diarrea" (panel D), respectively, corresponding to "fever", "cough", "back pain" and "diarrhea" in English translation.

\section{Compliance with ethical standards}

Conflict of interest The authors declare they have no conflict of interest.

Human and animal rights statement Not applicable.

Informed consent Not applicable.

In all panels, polynomial smoothed trendlines were drawn. The sudden rise in search volumes for "febbre" (panel A) observed on July 18th is presumably attributable to the 1976 Italian cult movie "Febbre da cavallo" (Horse fever) went on air on TV prime-time that same day

Med. https://doi.org/10.1007/s11739-020-02371-7(Ahead of print 25 May 2020)

2. Fu L, Wang B, Yuan T et al (2020) Clinical characteristics of coronavirus disease 2019 (COVID-19) in China: a systematic review and meta-analysis. J Infect 80(6):656-665. https://doi. org/10.1016/j.jinf.2020.03.041

3. Eysenbach G (2011) Infodemiology and infoveillance tracking online health information and cyberbehavior for public health. Am J Prev Med 40(5 Suppl 2):S154-S158. https://doi.org/10.1016/j. amepre.2011.02.006

Publisher's Note Springer Nature remains neutral with regard to jurisdictional claims in published maps and institutional affiliations.

\section{References}

1. Ciaffi J, Meliconi R, Landini MP, Ursini F (2020) Google trends and COVID-19 in Italy: could we brace for impact? Intern Emerg 